Coatings 2013, 3, 166-176; doi:10.3390/coatings3030166

\title{
Characterisation Studies of the Structure and Properties of As-Deposited and Annealed Pulsed Magnetron Sputtered Titania Coatings
}

\author{
Justyna Kulczyk-Malecka ${ }^{1}{ }^{*}$, Peter J. Kelly ${ }^{1}$, Glen West ${ }^{1}$, Gregory C.B. Clarke ${ }^{2}$ and \\ John A. Ridealgh ${ }^{3}$
}

1 Surface Engineering Group, Manchester Metropolitan University, Manchester M1 5GD, UK;

E-Mails: peter.kelly@mmu.ac.uk (P.J.K.); G.West@mmu.ac.uk (G.W.)

2 Pilkington United Kingdom Ltd., NSG Group, St Helens WA10 2RZ, UK;

E-Mail: Gregory.Clarke@nsg.com

3 Pilkington Technology Management Ltd., NSG Group, Lathom L40 5UF, UK;

E-Mail: John.Ridealgh@nsg.com

* Author to whom correspondence should be addressed; E-Mail: J.Kulczyk-Malecka@mmu.ac.uk; Tel.: +44-161-247-6432.

Received: 4 July 2013; in revised form: 26 August 2013 / Accepted: 30 August 2013 /

Published: 10 September 2013

\begin{abstract}
Titanium dioxide thin films are durable, chemically stable, have a high refractive index and good electro/photochemical proprieties. Consequently, they are widely used as anti-reflective layers in optical devices and large area glazing products, dielectric layers in microelectronic devices and photo catalytic layers in self-cleaning surfaces. Titania coatings may have amorphous or crystalline structures, where three crystalline phases of $\mathrm{TiO}_{2}$ can be obtained: anatase, rutile and brookite, although the latter is rarely found. It is known, however, that the structure of $\mathrm{TiO}_{2}$ coatings is sensitive to deposition conditions and can also be modified by post-deposition heat treatments. In this study, titania coatings have been deposited onto soda-lime glass substrates by reactive sputtering from a metallic target. The magnetron was driven in mid-frequency pulsed DC mode. The as-deposited coatings were analysed by micro Raman spectroscopy, X-ray diffraction (XRD), atomic force microscopy (AFM) and scanning electron microscopy (SEM). Selected coatings were annealed at temperatures in the
\end{abstract}


range $200-700{ }^{\circ} \mathrm{C}$ and re-analysed. Whilst there was weak evidence of a nanocrystallinity in the as-deposited films, it was observed that these largely amorphous low temperature structures converted into strongly crystalline structures at annealing temperatures above $400{ }^{\circ} \mathrm{C}$.

Keywords: titanium dioxide; magnetron sputtering; Raman; XRD

\section{Introduction}

Titanium dioxide is an important material in optical applications due to its high refractive index, high hardness and chemical resistance. It plays important role in solar control [1], self-cleaning [2], anti-reflective and low emissivity (Low-E) coatings. Low-E coatings are applied to large area architectural glazing to reduce heat losses from buildings. They combine high visible transparency with high reflectance in the far-infrared region. To achieve this combination of properties, Low-E coatings generally consist of dielectric-silver-dielectric multi-layer systems or stacks, where the thin $(\sim 10 \mathrm{~nm})$ silver layer reflects long wavelength IR back into the building and the dielectric layers both protect the silver and act as anti-reflectance layers [3]. Titania is commonly used as the dielectric layer [4] and all the layers are usually deposited by magnetron sputtering, which is considered to be one of the most important large-area coating technologies $[5,6]$. The market for low-E coatings has grown considerably in recent years due to environmental legislation and increased energy costs. To further expand the market, the next generation of Low-E coatings are increasingly being deposited onto toughenable glass, which is post-deposition annealed at temperatures of up to $650^{\circ} \mathrm{C}$. However, titania can exist in a number of crystalline forms with different properties and the final structure is dependent on both the deposition conditions and any post-deposition treatments [7]. Titania coatings usually form amorphous, anatase, rutile or mixed phase structures (a third phase, brookite, is rarely found in thin films). The refractive index increases from $n<2.3$ at $550 \mathrm{~nm}$ for an amorphous film to $n>2.6$ at $550 \mathrm{~nm}$ for a pure rutile phase film. Thus, the toughening process could potentially change the structure and therefore the proprieties, of the titania layers, which in turn could have a detrimental impact on the performance of the Low-E stack.

Many different techniques can be used to deposit $\mathrm{TiO}_{2}$ such as sol-gel process [8-10], chemical vapour deposition [11-15], ion beam depositions [16], and magnetron sputtering [17-21]. In this project the latter technique has been used to produce titania coatings, which were post-deposition annealed over a range of temperatures to allow their subsequent structural development to be investigated.

\section{Experimental Section}

Titanium dioxide films were deposited onto $4 \mathrm{~mm}$ thick soda-lime glass by reactive pulsed DC magnetron sputtering. Films were sputtered from standard planar magnetrons using a $99.5 \%$ purity metal target of a dimensions of $100 \mathrm{~mm} \times 300 \mathrm{~mm}$, driven by an Advanced Energy Pinnacle Plus power supply operating in pulsed DC mode at an average power of $1 \mathrm{~kW}$ and a pulse frequency of $100 \mathrm{kHz}$ and $5.0 \mu \mathrm{sec}$ 
off time (i.e., 50\% duty). The optical emission monitoring (OEM) system was used to control the amount of oxygen introduced into the system during films deposition. The optimal conditions were found to be when the OEM signal was set to $20 \%$ of the full metal signal. Argon gas was introduced into the chamber by a mass flow controller (MKS Instruments Ltd., Andover, MA, USA), and was set at 65 standard cubic centimetres per minute (SCCM). Coatings were deposited at a pressure of about $0.2 \mathrm{~Pa}$ and the substrate-magnetron separation was about $90 \mathrm{~mm}$.

Selected samples were post deposition annealed in air in the range $200-700{ }^{\circ} \mathrm{C}$ for $10 \mathrm{~min}$ and analysed by a wide range of techniques to determine film morphology, composition and crystalline structure.

The coating thickness was measured by a Dektak ${ }^{\circledR} 3 \mathrm{M}$ stylus profilometer (Vecco Instruments Inc., Plainview, TX, USA) and was determined to be close to $1.5 \mu \mathrm{m}$ in all cases.

The crystallographic proprieties of the film were performed using Bragg- Brentano mode on a Siemens D5000 Diffractometer D7 with $\mathrm{Cu} \mathrm{K \alpha}$ radiation and $\mathrm{Ni}$ filter and Scintillation detector. The angular step of the sample rotation in respect to the incident beam is $0.1^{\circ}$ and counting time is $15 \mathrm{~s} / \mathrm{step}$.

Raman spectroscopy (Renishaw inVia spectrometer with $514.4 \mathrm{~nm}$ wavelength of argon ion laser, Wotton-under-Edge, UK) was also carried out to further investigate the crystalline structure of the titania coatings before and after annealing as a comparison to the XRD analysis.

The surface morphology of the titanium dioxide coatings was investigated using scanning electron microscopy (SEM, Supra 40VP, Carl Zeiss GmbH, Munich, Germany ) operating at 1-3 kV and atomic force microscopy (AFM, MultiMode ${ }^{\mathrm{TM}}$ SPM with Nanoscope III controller with the WSXM software, Digital Instruments, Santa Barbara, CA, USA). Energy dispersive X-ray analysis with $40 \mathrm{~mm}^{2}$ silicon drift detector (Trident, EDAX Inc., Mahwah, NJ, USA) with an electron beam energy of $8 \mathrm{keV}$ was used to determine the stoichiometry of the deposited materials.

\section{Results and Discussion}

Titania samples deposited in this work were post-deposition annealed in the range $200-700{ }^{\circ} \mathrm{C}$ for $10 \mathrm{~min}$ in air. Selected samples were investigated by EDX analysis to determine the coating composition. The results suggest that samples deposited in this work show almost stoichiometric compositions of $\mathrm{TiO}_{2}$ consisting of 34 at\% (61 wt \%) of Ti and 66 at\% (39 wt \%) of $\mathrm{O}_{2}$.

SEM analysis was carried out to investigate film morphology. The image shown in Figure 1 presents the fracture section of the as-deposited sample. The coating has a dense structure and a reasonably smooth surface morphology, with some small defects existing on the surface.

Micro-Raman spectroscopy was performed to investigate changes in the crystalline structure of the titania coatings after annealing. Titanium dioxide can form three main crystalline structures: tetragonal anatase and rutile, which belong to the space group $D_{4 h}^{19}$ and $D_{4 h}^{14}$, respectively, and lower symmetry orthorhombic brookite ( $D_{2 h}$ space group representation) [22,23]. Factor group analysis of anatase indicates the existence of 15 optical modes with the following representation of normal vibrations: $1 \mathrm{~A}_{1 \mathrm{~g}}+1 \mathrm{~A}_{2 \mathrm{u}}+2 \mathrm{~B}_{1 \mathrm{~g}}+1 \mathrm{~B}_{2 \mathrm{u}}+3 \mathrm{E}_{\mathrm{g}}+2 \mathrm{E}_{\mathrm{u}}$ [24]. Within this representation $1 \mathrm{~A}_{1 \mathrm{~g}}, 2 \mathrm{~B}_{1 \mathrm{~g}}, 3 \mathrm{E}_{\mathrm{g}}$ are Raman active, whereas the remaining modes are active in Infrared [24]. 
Figure 1. SEM images of the fracture section of as-deposited titania sample deposited onto float glass substrate.

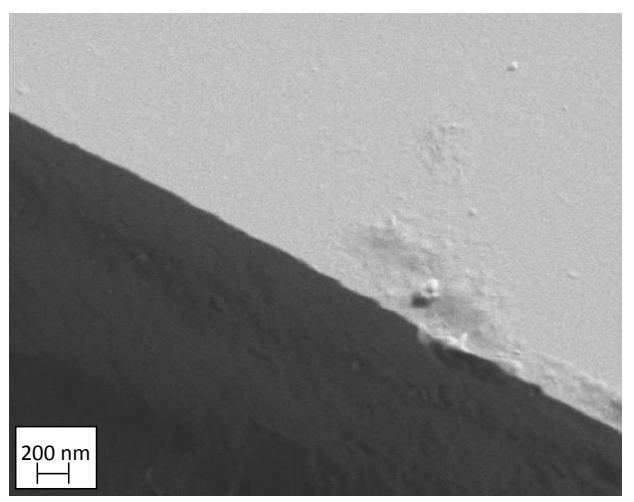

Raman analysis gives information about the nature of the bonds in a structure and there is substantial evidence indicating that the peak position, shape and intensity of Raman peaks are related to sub-stoichiometric defects, quantum confinement effects, crystal sizes, nanocrystallinity and large interfacial areas $[22,23,25,26]$. Spectra obtained from the titania films produced in this work were compared against those obtained for pure titania nano-crystals to allow any variations in phase, stoichiometry or degree of crystallisation in the analysed films to be identified.

Figure 2 represents Raman spectra taken from the as-deposited sample, and samples annealed at $200{ }^{\circ} \mathrm{C}$ and $300{ }^{\circ} \mathrm{C}$. The spectrum from a nanocrystalline rutile standard (standards provided by Cristal Global, Stallingborough, UK) is also included in the figure showing two characteristic Raman shifts at 447 and $612 \mathrm{~cm}^{-1}$. The samples show relatively low intensity peaks shifted to lower and higher numbers at $447 \mathrm{~cm}^{-1}$ and $612 \mathrm{~cm}^{-1}$, respectively. The rutile shoulder peak at $237 \mathrm{~cm}^{-1}$ in all the samples is overlaid with a lower Raman shift peak situated at about $185 \mathrm{~cm}^{-1}$, which may indicate a mixture of anatase and brookite formation. Anatase is represented by a high intensity peak at $144 \mathrm{~cm}^{-1}$ and a weak peak at $197 \mathrm{~cm}^{-1}$, whereas brookite shows a strong shift at $153 \mathrm{~cm}^{-1}$. Moreover, in the sample annealed at $200{ }^{\circ} \mathrm{C}$ the peak at $447 \mathrm{~cm}^{-1}$ has significantly decreased, showing a low intensity broad peak. This implies that even though peak positions in these samples are characteristic to crystalline rutile formation there is no long range ordering in these samples and the Raman shifts are most likely represented by amorphous vibrations. It has been suggested that peak broadening occurs due to nanocrystallinity and quantum confinement effects, and that there is a characteristic dependency between grain size and peak position and broadening in Raman analysis [23,25-27]. Finally Li Bassi et al. [22] pointed out that materials with smaller particles $(\sim 4.4 \mathrm{~nm})$ have Raman spectrum similar to that of amorphous materials, which could also be the case here.

Figure 3 presents samples annealed at $400{ }^{\circ} \mathrm{C}, 600{ }^{\circ} \mathrm{C}$ and $700{ }^{\circ} \mathrm{C}$ aligned with an anatase nanocrystalline powder standard (characteristic Raman shifts at 144, 399, 515 and $639 \mathrm{~cm}^{-1}$ ). For all these samples a distinct anatase structure can be seen. Samples annealed at the temperature range of $400-700{ }^{\circ} \mathrm{C}$ show the degradation of the rutile-like structure in favour of very strong anatase peaks formation. 
Figure 2. Raman spectra of titania coatings from the as-deposited sample and samples annealed at 200 and $300{ }^{\circ} \mathrm{C}$, aligned with the rutile standard.

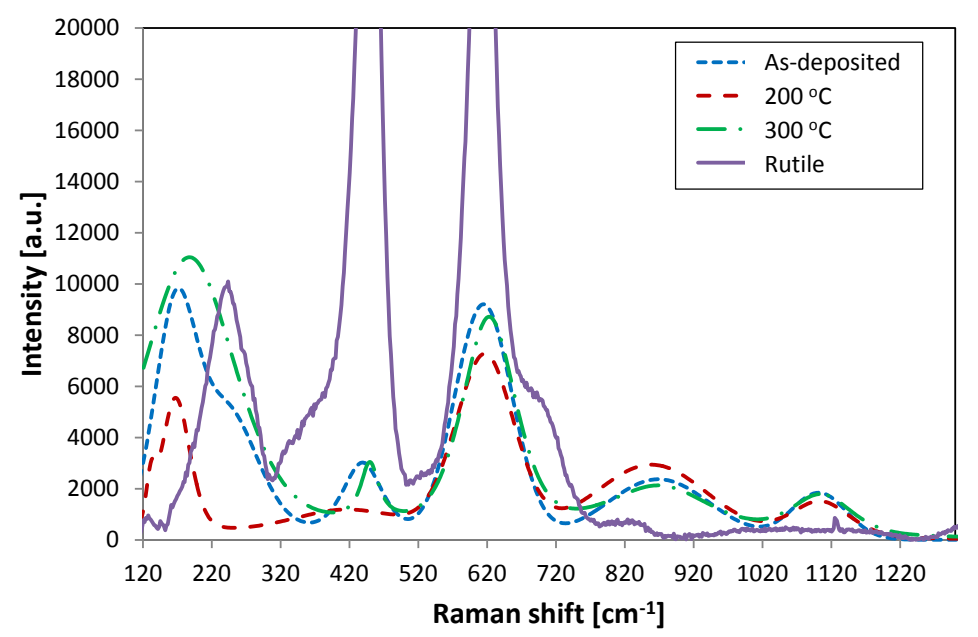

Figure 3. Raman spectra collected from samples annealed at 400, 600 and $700{ }^{\circ} \mathrm{C}$ and anatase standard.

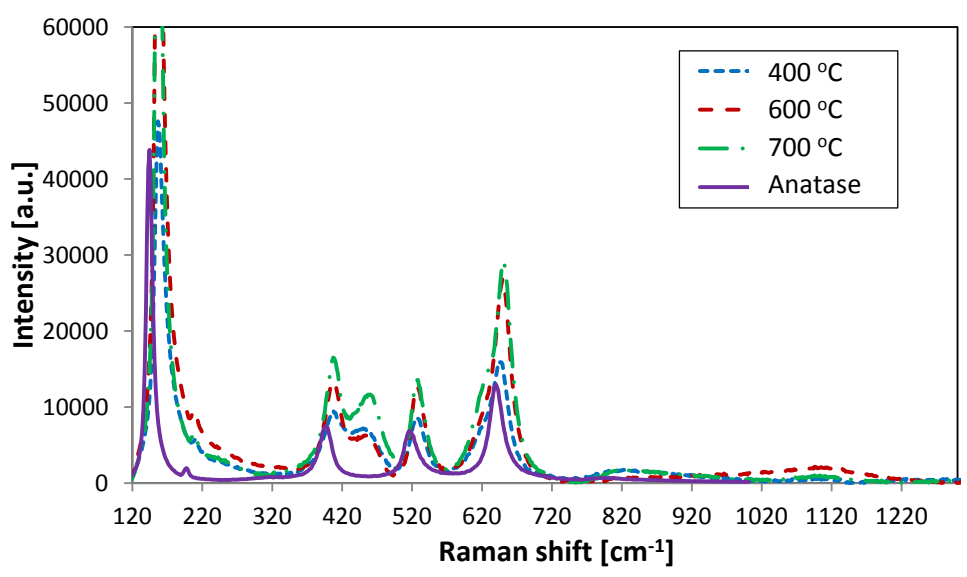

Moreover, a peak at about $460 \mathrm{~cm}^{-1}$ that appears in these analysed samples probably indicates the presence of the rutile phase in the crystal structure. This peak increases with rising annealing temperature. Additionally, in the case of sample annealed at $700{ }^{\circ} \mathrm{C}$ a weak shoulder is presented at $620 \mathrm{~cm}^{-1}$, which also represents one of the characteristic shifts in the rutile structure. This may suggest that the titania structure is shifting from anatase to the rutile phase, which would be expected since rutile tends to form in highly energetic processes, therefore high temperature annealing may initiate the rutile forming process. Some quite significant peak up shifting and broadening was detected, which could be caused by non-stoichiometric composition of the material or by small particle sizes [23]. The broad, weak peaks at about $1100 \mathrm{~cm}^{-1}$ arise from the glass surface, as found by Xie et al. [28].

To investigate the structural changes at higher temperatures one additional sample was annealed at $700{ }^{\circ} \mathrm{C}$ for $10 \mathrm{~min}$ in air. SEM micrographs presented in Figure 4a,b show visible changes in the surface topography. Features on the film surface appear to have been caused by post deposition crystallisation 
processes after treatment at relatively high temperature. To compare if there is any difference in crystal structure between the surface region and the features observed by SEM, Raman scans were taken from the faceted area and the surrounding surface region, respectively (see Figure 5). In both cases analysis showed that the crystalline structure was the same, but there are differences in peak intensities. It may suggest that these regions have the same crystal structure as the surrounding surface. On the other hand, micro-Raman is not a surface specific technique, and the laser, which penetrates to a depth of about $1 \mu \mathrm{m}$, picks up signals not just from the sample surface but also from regions underneath.

Figure 4. SEM micrograph of the surface of the titania sample, deposited onto float glass and annealed at $700{ }^{\circ} \mathrm{C}$ : (a) at lower magnification scan and (b) at higher magnification scan.

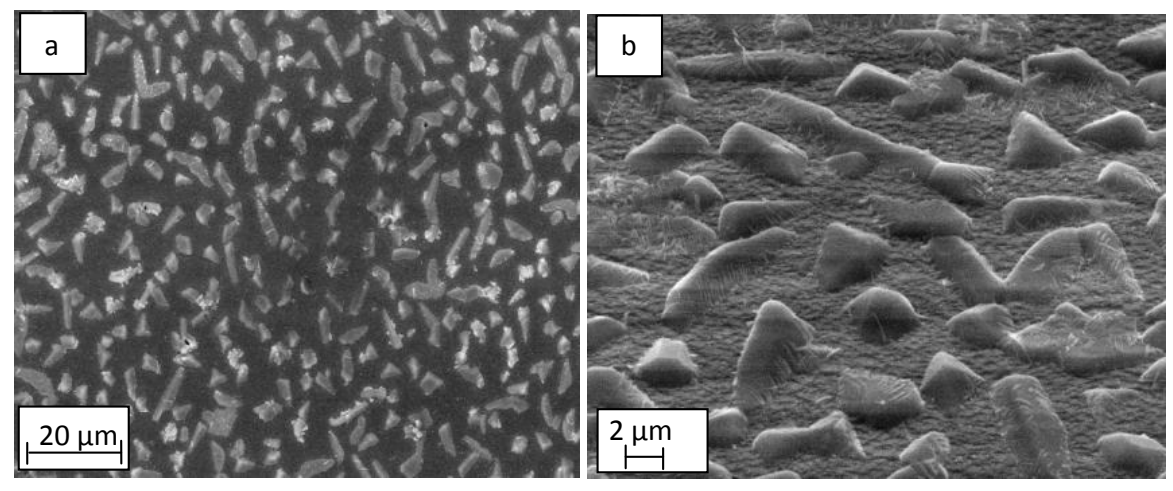

Figure 5. Raman images of sample annealed at $700{ }^{\circ} \mathrm{C}$. Red-collected from surface, blue-from grain.

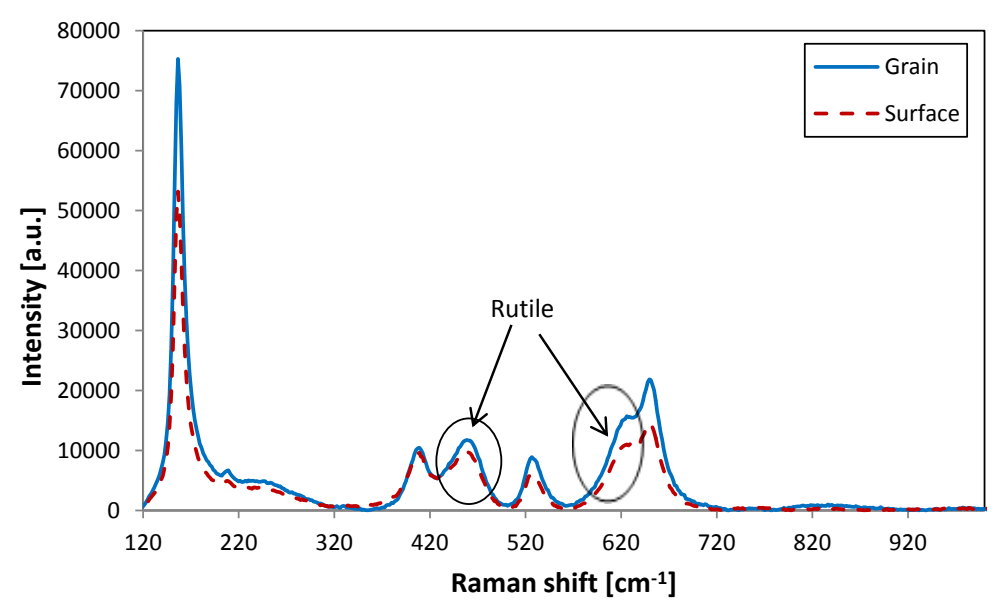

Figure 5 shows the Raman spectra obtained from both surface and faceted region of the sample annealed at $700{ }^{\circ} \mathrm{C}$. Both scans present the same shapes for the Raman peaks (same shifts detected), however they differ slightly in the intensities. This may be due to higher concentration of the detected mixed anatase/rutile crystals in the grain areas, as sharper and more intensive peaks indicate higher crystallinity. This suggests that the grains are regions of improved crystallinity, which arose during the high temperature treatment. Following that, the spectrum obtained from the sample annealed at $700{ }^{\circ} \mathrm{C}$ for 10 min shows mixed anatase/rutile structure. A strong peak at $445 \mathrm{~cm}^{-1}$ wavelength and peak shoulder at 
$615 \mathrm{~cm}^{-1}$ is indicative of a rutile structure, which is known to be formed by higher energy processes; therefore increasing temperature allows a transformation to occur from meta-stable anatase to rutile [17]. Unfortunately, further investigations of titania films phase transformation due to high temperature treatment was restricted by the glass substrate properties, which softens when annealed at temperatures above $700{ }^{\circ} \mathrm{C}$.

The XRD analysis was carried out to determine the crystalline structure of titania coatings. The analysis was carried out on an as-deposited $\mathrm{TiO}_{2}$ sample and samples annealed at 200, 300, 400 and $700{ }^{\circ} \mathrm{C}$. Figure 6 shows the diffraction patterns obtained from these samples.

Figure 6. XRD diffractograms collected from $\mathrm{TiO}_{2}$ as-deposited sample and annealed at 200, 300,400 and $700{ }^{\circ} \mathrm{C}$ for $10 \mathrm{~min}$. Lines represent peak position for anatase (red) and rutile (black) phases, respectively.

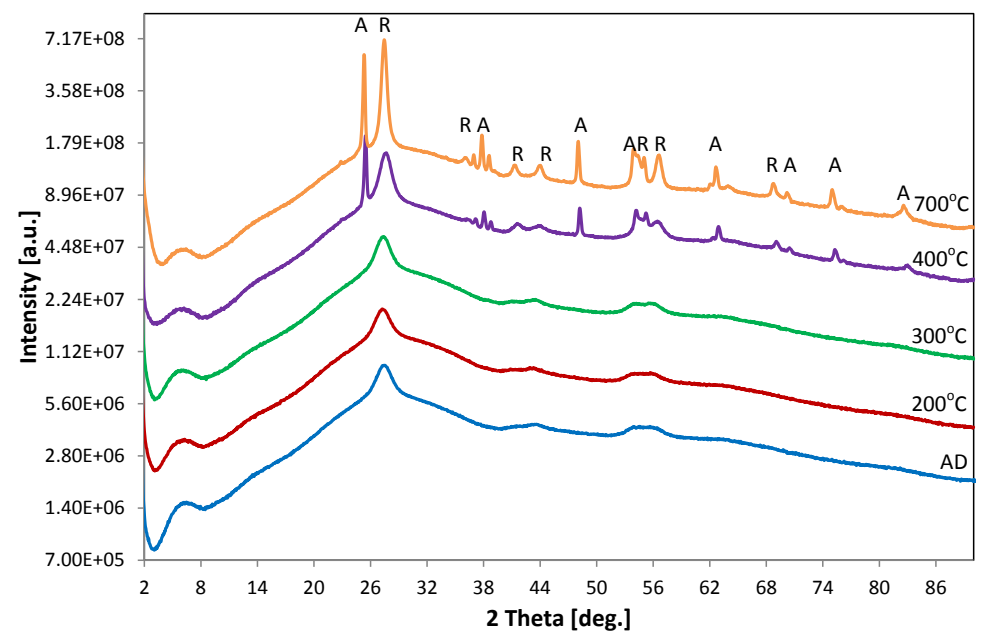

XRD analysis indicates that samples treated at temperatures below $400{ }^{\circ} \mathrm{C}$ show an unknown or weakly crystalline phase, which could be rutile-based. This structure has been determined as consisting of a very small grain size $(\sim 3 \mathrm{~nm})$. In samples annealed at $400{ }^{\circ} \mathrm{C}$ and above, evidence for a two-phase anatase and rutile structure can be distinguished. In addition, based on the peak widths, the crystallite size for anatase is much larger than for rutile, which could be the reason why in the Raman analysis it was detected more easily than rutile in samples annealed at $400-600{ }^{\circ} \mathrm{C}$.

Finally, the XRD results show that the sample annealed at $700{ }^{\circ} \mathrm{C}$ consists of mixed anatase/rutile phases in the coatings, similar to what was found from Raman analysis for this sample. Nevertheless, Raman spectra collected from samples annealed at relatively high temperatures $\left(400-600{ }^{\circ} \mathrm{C}\right)$ suggested that anatase is the leading form of titania presented in these samples. This may be caused by the significant difference in the grain sizes between rutile and anatase. As mentioned earlier, particle sizes are one of the main factors that influence Raman analysis as well as XRD. Generally, relatively small grains represent broader, lower intensity peaks, which furthermore in Raman may also cause peak shifting. Therefore, if the anatase has significantly larger grains than the rutile in titania coatings characterised in this study it could be picked up as a dominant phase in Raman spectroscopy. 
Table 1 shows the grain sizes calculated using the full width half maximum of the peaks from the Debye-Scherrer equation [29].

Table 1. Crystallite size calculated for titania samples characterised by XRD.

\begin{tabular}{cccc}
\hline Sample & $\begin{array}{c}\text { Crystallite size } \\
(\mathbf{1 1 0}) \text { Rutile [nm] }\end{array}$ & $\begin{array}{c}\text { Crystallite size (101) } \\
\text { Anatase [nm] }\end{array}$ & $\begin{array}{c}\text { Crystallite size Amorphous } \\
\text { Phase [nm] }\end{array}$ \\
\hline $\mathrm{AD}$ & - & - & 3.3 \\
$200{ }^{\circ} \mathrm{C}$ & - & - & 3.4 \\
$300^{\circ} \mathrm{C}$ & - & - & 3.5 \\
$400^{\circ} \mathrm{C}$ & 4.7 & 77 & - \\
$700{ }^{\circ} \mathrm{C}$ & 14 & 110 & - \\
\hline
\end{tabular}

In order to investigate surface roughness atomic force microscopy (AFM) analysis was conducted. Surface roughness was investigated in the as-deposited sample and the sample annealed at $600{ }^{\circ} \mathrm{C}$ for $10 \mathrm{~min}$. Figure 7 shows $5 \mu \mathrm{m} \times 5 \mu \mathrm{m}$ images of the surface topography of these coating. Table 2 shows root-mean-square (RMS) and roughness average (Ra) values for both samples. The values are slightly higher for the as-deposited sample, which suggests that during heat treatment grain sizes increase, filling the free spaces and/or valleys on the coating surface, and hence surface roughness decreases in the annealed film. However, the difference in roughness values is not very large, therefore it should not influence coating performance.

Figure 7. (a) AFM image collected from as-deposited titania sample; (b) AFM image collected from titania sample post-deposition annealed at $600{ }^{\circ} \mathrm{C}$ deposited onto float glass substrate.
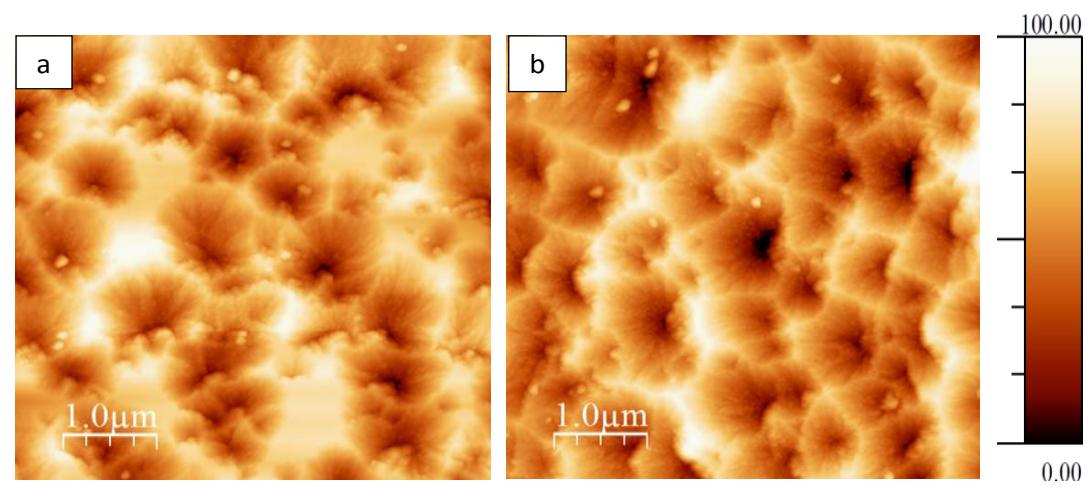

Table 2. Roughness average and root-mean-square values obtained from AFM analysis for as-deposited and annealed at $600{ }^{\circ} \mathrm{C}$ titania samples.

\begin{tabular}{ccc}
\hline $\mathbf{T i O}_{\mathbf{2}}$ sample & Ra [nm] & RMS [nm] \\
\hline As-deposited & 13.8 & 16.9 \\
Annealed at $600{ }^{\circ} \mathrm{C}$ & 13.1 & 16.4 \\
\hline
\end{tabular}




\section{Conclusions}

These studies showed that the as-deposited magnetron sputtered titania coatings had either amorphous structures or possibly rutile-based nanocrystalline structures. This structure transforms into a mixture of anatase and rutile crystalline phases when the samples undergo post-deposition heat treatment at temperatures of up to $600{ }^{\circ} \mathrm{C}$. Sample annealed at $700{ }^{\circ} \mathrm{C}$ are more strongly crystalline, but are still mixed phase with rutile perhaps becoming more dominant. Since rutile is known to be formed by more energetic processes than anatase, a total anatase-to-rutile transformation would be expected to occur after annealing at temperatures higher than $700{ }^{\circ} \mathrm{C}$, which could not be studied here due to the limitations of the glass substrate; soda-lime glass starts softening at about $726^{\circ} \mathrm{C}$.

SEM micrographs showed generally smooth and dense film surfaces, with some small defects existing on the surface. It was shown that coatings undergo re-crystallisation during annealing at $700{ }^{\circ} \mathrm{C}$. Large facetted grains were noticed after heat treatment at elevated temperatures. Raman analysis of these grains has not confirmed a specific crystalline phase of titanium dioxide, rather mixed anatase-rutile crystals. EDX analysis showed that the titania coatings deposited in this work had stoichiometric compositions. AFM analysis showed that the surface roughness (Ra values) of the $\mathrm{TiO}_{2}$ samples were between 13 and $14 \mathrm{~nm}$, and did not vary significantly after annealing at $600{ }^{\circ} \mathrm{C}$.

Overall findings from this study show that annealing temperature plays an important role in the structural evolution of titania films. Samples which were subjected to the highest annealing temperature show mixed crystalline structures, with a tendency to the rutilisation of the $\mathrm{TiO}_{2}$ at higher temperatures. Samples annealed at lower temperatures show amorphous or weakly crystalline structures. Therefore, annealing conditions applied in the Low-E glass toughening process should be carefully chosen to achieve the desired structure of the titania coating.

\section{Acknowledgments}

Authors would like to thank to Nadia Stelmashenko from Wolfson College Cambridge for AFM analysis, Vlad Vishnyakov from Dalton Research Institute, MMU for EDX and SEM analysis and Intertek MSG for XRD analysis.

\section{Conflicts of Interest}

Authors declare no conflict of interest.

\section{References}

1. O'Regan, B.; Grätzel, M. A low-cost, high-efficiency solar cell based on dye sensitized colloidal $\mathrm{TiO}_{2}$ films. Nature 1991, 353, 737-740.

2. Piispanen, M.; Hupa, L. Comparison of self-cleaning properties of three titania coatings on float glass. App. Surf. Sci. 2011, 258, 1126-1131. 
3. Glaser, H.J. Large Area Glass Coating; Von Ardenne Anglgentechnik GmbH: Dresden, Germany, 2000.

4. Chiba, K.; Takahashi, T.; Kageyama, T.; Oda, H. Low-emissivity coating of amorphous diamond-like carbon/Ag-alloy multilayer on glass. App. Surf. Sci. 2005, 246, 48-51.

5. Ando, E.; Suzuki, S.; Aomine, N.; Miyazaki, M.; Tada, M. Sputtered silver-based low-emissivity coatings with high moisture durability. Vacuum 2000, 59, 792-799.

6. Hammarberg, E.; Roos, A. Antireflection treatment of low-emitting glazings for energy efficient windows with high visible transmittance. Thin Solid Films 2003, 442, 222-226.

7. Mattox, D.M. Handbook of Physical Vacuum Deposition (PVD) Processing; Noyes Publications: Westwood, NJ, USA, 1998.

8. Yu, J.C.; Yu, J.; Zhao, J. Enhanced photocatalytic activity of mesoporous and ordinary $\mathrm{TiO}_{2}$ thin films by sulfuric acid treatment. App. Cat. B Environ. 2002, 36, 31-43.

9. Vorotilov, K.A.; Orlova, E.V.; Petrovsky, V.I. Sol-gel $\mathrm{TiO}_{2}$ films on silicon substrates. Thin Solid Films 1992, 207, 180-184.

10. Yoko, T.; Hu, L.; Kozuka, H.; Sakka, S. Photoelectrochemical properties of $\mathrm{TiO}_{2}$ coating films prepared using different solvents by the sol-gel method. Thin Solid Films 1996, 283, 188-195.

11. Yates, H.M.; Nolan, M.G.; Shell, D.W.; Pemble, M.E. The role of nitrogen doping on the development of visible light-induced photocatalytic activity in thin $\mathrm{TiO}_{2}$ films grown on glass by chemical vapour deposition. J. Photochem. Photobiol. A Chem. 2006, 179, 213-223.

12. Lu, J.-P.; Wang, J.; Raj, R. Solution precursor chemical vapor deposition of titanium oxide thin films. Thin Solid Films 1991, 204, L13-L17.

13. Yeung, K.S.; Lam, Y.W. A simple chemical vapour deposition method for depositing thin $\mathrm{TiO}_{2}$ films. Thin Solid Films 1983, 109, 169-178.

14. Bessergenev, V.G.; Khmelinskii, I.V.; Pereira, R.J.F.; Krisuk, V.V.; Turgambaeva, A.E.; Igumenov, I.K. Preparation of $\mathrm{TiO}_{2}$ films by CVD method and its electrical, structural and optical properties. Vacuит 2002, 64, 275-279.

15. Lee, W.G.; Woo, S.I.; Kim, J.C.; Choi, S.H.; Oh, K.H. Preparation and properties of amorphous $\mathrm{TiO}_{2}$ thin films by plasma enhanced chemical vapour deposition. Thin Solid Films 1994, 237, 105-111.

16. Zhang, F.; Jin, S.; Mao, Y.; Zheng, Z.; Chen, Y.; Liu, X. Surface characterization of titanium oxide films synthesized by ion beam enhanced deposition. Thin Solid Films 1997, 310, 29-33.

17. Löbl, P.; Huppertz, M.; Mergel, D. Nucleation and growth in $\mathrm{TiO}_{2}$ films prepared by sputtering and evaporation. Thin Solid Films 1994, 251, 72-79.

18. Mardare, D.; Hones, P. Optical dispersion analysis of $\mathrm{TiO}_{2}$ thin films based on variable-angle spectroscopic ellipsometry measurements. Mat. Sci. Eng. B 1999, 68, 42-47.

19. Gratzel, M. Nanocrystalline solar cells. Renew. Energ. 1994, 5, 118-133.

20. Meng, L.-J.; dos Santos, M.P. Investigations of titanium oxide films deposited by d.c. reactive magnetron sputtering in different sputtering pressures. Thin Solid Films 1993, 226, $22-29$. 
21. Schiller, S.; Beister, G.; Sieber, W.; Schirmer, G.; Hacker, E. Influence of deposition parameters on the optical and structural properties of $\mathrm{TiO}_{2}$ films produced by reactive d.c. plasmatron sputtering. Thin Solid Films 1981, 83, 239-245.

22. Li Bassi, A.; Cattaneo, D.; Russo, V.; Bottani, C.E.; Barborini, E.; Mazza, T.; Piseri, P.; Milani, P.; Ernst, F.O.; Wegner, K.; et al. Raman spectroscopy characterization of titania nanoparticles produced by flame pyrolysis: The influence of size and stoichiometry. J. Appl. Phys. 2005, 98, 1-9.

23. Giolli, C.; Borgioli, F.; Credi, A.; Di Fabio, A.; Fossati, A.; Miranda, M.M.; Parmeggiani, S.; Rizzi, G.; Scrivani, A.; Troglio, S.; et al. Characterization of $\mathrm{TiO}_{2}$ coatings prepared by a modified electric arc-physical vapour deposition system. Surf. Coat. Technol. 2007, 202, 13-22.

24. Sekiya, T.; Ohta, S.; Kamei, S.; Hanakawa, M.; Kurita, S. Raman spectroscopy and phase transition of anatase $\mathrm{TiO}_{2}$ under high pressure. J. Phys. Chem. Solids 2001, 62, 717-721.

25. Khan, A.F.; Mehmood, M.; Aslam, M.; Shah, S.I. Nanostructured multilayer $\mathrm{TiO}_{2}$-Ge films with quantum confinement effects for photovoltaic applications. J. Colloid Interface Sci. 2010, 343, 271-280.

26. Karunagaran, B.; Kim, K.; Mangalaraj, D.; Yi, J.; Velumani, S. Structural, optical and Raman scattering studies on DC magnetron sputtered titanium dioxide thin films. Sol. Energy Mater. Sol. Cells 2005, 88, 199-208.

27. Balaji, S.; Djaoued, Y.; Robichaud, J. Photon confinement studies in nanocrystalline anatase- $\mathrm{TiO}_{2}$ thin films by micro-Raman spectroscopy. J. Raman Spectrosc. 2006, 37, 1416-1422.

28. Xie, Y.; Zhao, X.; Tao, H.; Zhao, Q.; Liu, B.; Yuan, Q. The influence of $\mathrm{O}_{2}$ partial pressure on the structure and surface wettability of C-modified $\mathrm{TiO}_{2}$ films prepared by magnetron co-sputtering. Chem. Phys. Letters 2008, 457, 148-153.

29. Hammond, C. The Basics of Crystallography and Diffraction; Oxford University Press Inc.: New York, NY, USA, 2001.

(C) 2013 by the authors; licensee MDPI, Basel, Switzerland. This article is an open access article distributed under the terms and conditions of the Creative Commons Attribution license (http://creativecommons.org/licenses/by/3.0/). 